\title{
Definition der hyperbaren Oxygenation (HBO)
}

Die hyperbare Oxygenation, kurz HBO, ist ein medizinisch-therapeutisches Verfahren, bei welchem ein Patient in einer Überdruckkammer 100\% Sauerstoff unter einem Umgebungsdruck höher als auf Meeresniveau ( $>1$ atmosphere absolute, ATA) ventiliert. Ausschlaggebend dabei sind die Kombination von reinem Sauerstoff und Überdruckumgebung sowie die systemische Applikation via Ventilation. Eine Beatmung mit $100 \%$ Sauerstoff unter normobaren Bedingungen bzw. die rein topische Anwendung von Sauerstoff in einer Überdruckkammer entsprechen nicht der Definition der HBO (Gill und Bell 2004; Lampl et al. 2009a).

D. Maurer, Hyperbare Oxygenation und Tauchmedizin, essentials, 